\title{
Effect of Cooling Rate and Ti Addition on the Microstructure and Mechanical Properties in As-cast Condition of Hypereutectic High Chromium Cast Irons
}

\author{
Qiang LIU, ${ }^{1) *}$ Hongwei ZHANG ${ }^{2)}$ Qiang WANG ${ }^{21}$ Xiangkui ZHOU, ${ }^{21}$ Pär G. JÖNSSON ${ }^{11}$ and Keiji NAKAJIMA ${ }^{1) *}$ \\ 1) KTH Royal Institute of Technology, Department of Materials Science and Engineering, Stockholm, SE-100 44 Sweden. \\ 2) Northeastern University, Key Laboratory of Electromagnetic Processing of Materials, Shenyang, 110004 P.R. China.
}

(Received on June 12, 2012; accepted on August 16, 2012)

\begin{abstract}
The effect of cooling rate and Ti additions on the mechanical properties and carbides characteristics such as morphology, size distribution and composition was studied in high-chromium cast irons containing $\mathrm{Fe}-17$ mass $\% \mathrm{Cr}-4$ mass $\% \mathrm{C}$. Based on the size distribution, composition and morphology, $\mathrm{M}_{7} \mathrm{C}_{3}$ type carbides were roughly classified into "primary $\mathrm{M}_{7} \mathrm{C}_{3}$ carbides" and "eutectic $\mathrm{M}_{7} \mathrm{C}_{3}$ carbides" with a $11.2 \mu \mathrm{m}$ border size. Thereafter, the change of the solidification structure and especially the refinement of carbides size were determined. It was found that both the size and number values should be summarized systematically for primary $\mathrm{M}_{7} \mathrm{C}_{3}$ carbides and eutectic $\mathrm{M}_{7} \mathrm{C}_{3}$ carbides, respectively. Also, TiC carbides with a high formation temperature can not only act as a nuclei of $\mathrm{M}_{7} \mathrm{C}_{3}$ carbides, but they also contain a Ti(C, $\mathrm{N})$ core. In the as-cast condition, the bulk hardness of the cast irons increases with an increased Ti content. In addition, the wear loss increases with an increased Ti content. Neither the bulk hardness nor the wear loss did change too much with an increased cooling rate.
\end{abstract}

KEY WORDS: high chromium cast irons; cooling rate; Ti addition; carbides size distributions; $\mathrm{M}_{7} \mathrm{C}_{3}$; TiC.

\section{Introduction}

High chromium cast irons (HCCIs) are considered as one of the most useful wear resistance materials and their usage are widely spread. The wear performance level of hypereutectic HCCIs is mainly controlled by a high volume fraction (30 to $60 \%$ ) of $\mathrm{M}_{7} \mathrm{C}_{3}$ type carbides $\left(1200-1600 \mathrm{HV}^{1)}\right.$ ). In addition, they contain larger "primary $\mathrm{M}_{7} \mathrm{C}_{3}$ carbides" and smaller "eutectic $\mathrm{M}_{7} \mathrm{C}_{3}$ carbides". These carbides will precipitate during the cooling and solidification and will influence the final material properties. Therefore, many investigations have been executed with the aim of refining the solidification structure and improving the properties of hypereutectic HCCIs. Here, additions of alloy elements have been used to form the $\mathrm{NaCl}$ type carbides, such as $\mathrm{Ti}$, $\mathrm{Nb}, \mathrm{V}$ etc. ${ }^{2-9)}$

For $\mathrm{Ti}$ additions, it was reported that the $\mathrm{NaCl}$ type carbide such as $\mathrm{TiC}$ carbide can act as heterogeneous nuclei for the precipitation of $\mathrm{M}_{7} \mathrm{C}_{3}$ type carbides during the cooling and solidification of the melt. ${ }^{2-4)}$ This, in turn, results in significant refinements of the final carbides size. Moreover, the size, volume fraction and distribution of these carbides will also affect the final properties of the hypereutectic HCCIs significantly.

At present, a few reports discuss how the carbide size distribution influences their final solidification structure and

* Corresponding author: E-mail: qiangliu@kth.se,nakajima@mse.kth.se DOI: http://dx.doi.org/10.2355/isijinternational.52.2210 properties. However, they show only the effects of the average diameter and volume fraction of the total amount of carbides on the material properties. ${ }^{2-5,7)}$ In addition, they have not classified the $\mathrm{M}_{7} \mathrm{C}_{3}$ type carbides into "primary carbides" and "eutectic carbides". Nor have these studies presented information on their border size.

In the current study, the effect of the cooling rate and $\mathrm{Ti}$ additions on the microstructure and mechanical properties of the hypereutectic HCCIs, with a main composition of $\mathrm{Fe}-$ 17 mass \%.Cr-4 mass\%.C, is investigated in the as-cast condition. Here, the cooling rates were controlled using three kinds of molds: sand, graphite and metal. From the view point of the size distribution, composition and morphology, the $\mathrm{M}_{7} \mathrm{C}_{3}$ type carbides are roughly classified into "primary $\mathrm{M}_{7} \mathrm{C}_{3}$ carbides" and "eutectic $\mathrm{M}_{7} \mathrm{C}_{3}$ carbides". Moreover, their effect on the solidification structure and properties of the hypereutectic HCCIs is discussed. In addition, the effect of the $\mathrm{NaCl}$ type carbide such as $\mathrm{TiC}$ carbide on the microstructure and material properties is also discussed.

\section{Experimental}

\subsection{Procedure}

Based on the requirements during actual production, melts were prepared in a laboratory furnace. High-carbon ferrochromium ( $\mathrm{Fe}-8$ mass $\% \mathrm{C}-60$ mass $\% \mathrm{Cr}$ ), ferro-molybdenum ( $\mathrm{Fe}-0.05$ mass $\% \mathrm{C}-58.4$ mass $\% \mathrm{Mo})$, pure iron, pig iron ( $\mathrm{Fe}-$ 3.8 mass $\% \mathrm{C}-0.34$ mass $\% \mathrm{Mn}-1.8$ mass $\% \mathrm{Si}$ ), ferro-titanium (Fe-30 mass\%Ti), ferro-manganese (Fe-75.9 mass\%Mn), 
Table 1. Chemical compositions of high chromium cast irons (HCCIs) used in the experiments (mass.\%).

\begin{tabular}{|c|c|c|c|c|c|c|c|c|c|c|c|c|}
\hline Mold & $\mathrm{C}$ & $\mathrm{Cr}$ & $\mathrm{Ti}$ & $\mathrm{Mn}$ & Mo & $\mathrm{Ni}$ & $\mathrm{Si}$ & $\mathrm{N}$ & $\mathrm{S}$ & $\mathrm{O}$ & $\mathrm{P}$ & $\mathrm{Fe}$ \\
\hline \multirow{2}{*}{ Sand } & 4.01 & 16.2 & - & 2.04 & 1.01 & 1.24 & 0.775 & 0.020 & 0.018 & 0.0086 & 0.026 & Bal. \\
\hline & 3.79 & 17.0 & 1.53 & 2.08 & 1.05 & 1.09 & 0.416 & 0.016 & 0.017 & 0.014 & 0.025 & Bal. \\
\hline \multirow{4}{*}{ Graphite } & 4.9 & 16.4 & - & 1.59 & 0.75 & 1.09 & 0.845 & 0.019 & 0.022 & 0.0046 & 0.025 & Bal. \\
\hline & 4.03 & 15.6 & 0.74 & 1.72 & 0.93 & 1.08 & 0.992 & 0.014 & 0.020 & 0.0047 & 0.023 & Bal. \\
\hline & 4.01 & 17.4 & 1.48 & 1.91 & 0.89 & 1.11 & 0.951 & 0.015 & 0.017 & 0.011 & 0.024 & Bal. \\
\hline & 3.91 & 17.5 & 3.36 & 1.95 & 1.01 & 1.08 & 0.966 & 0.025 & 0.025 & 0.031 & 0.022 & Bal. \\
\hline \multirow{2}{*}{ Metal } & 3.92 & 14.7 & - & 1.950 & 0.95 & 1.05 & 0.529 & 0.015 & 0.020 & 0.0037 & 0.024 & Bal. \\
\hline & 3.90 & 16.8 & 1.06 & 1.95 & 0.99 & 1.15 & 0.708 & 0.014 & 0.014 & 0.0094 & 0.024 & Bal. \\
\hline
\end{tabular}
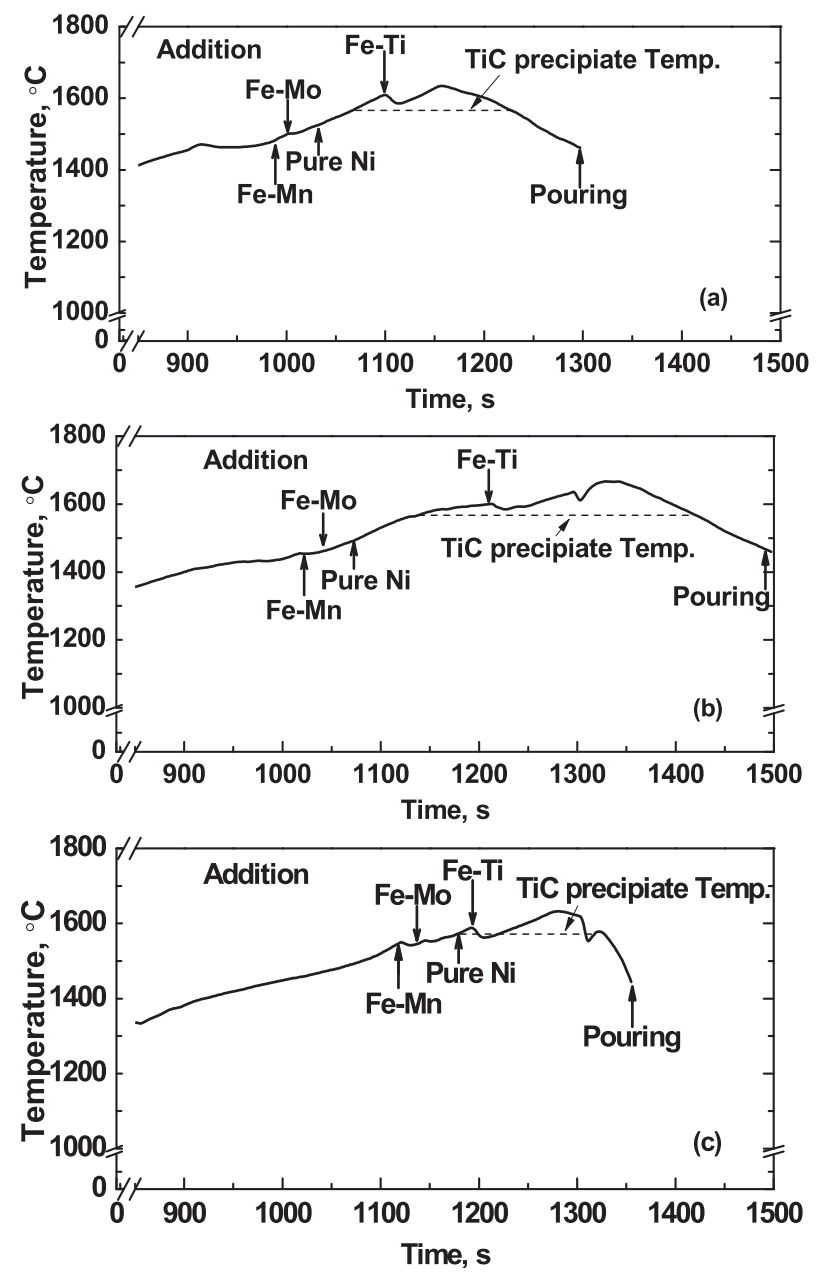

Fig. 1. Schematic diagram of the melting process of hypereutectic HCCIs with 1.5 mass\% Ti addition. (a) Sand mold, (b) Graphite mold, (c) Metal mold.

and pure nickel were melted in a $8 \mathrm{~kg}$ capacity graphite crucible. This was done using a medium frequency induction furnace $(45 \mathrm{Kw}, 7 \mathrm{kHz}$ ) and using an air atmosphere.

The alloy compositions are shown in Table 1. Pure iron, pig iron and high carbon ferro-chromium were first melted. Then, ferro-manganese and ferro-molybdenum were added. At last, pure nickel and ferro-titanium were added into this mother alloy. The holding time over the $\mathrm{TiC}$ precipitation temperature was controlled as $3 \mathrm{~min} \pm 1 \mathrm{~min}$, in order to prevent the agglomeration of TiC carbides precipitation. Finally, the molten hypereutectic HCCIs were poured into the

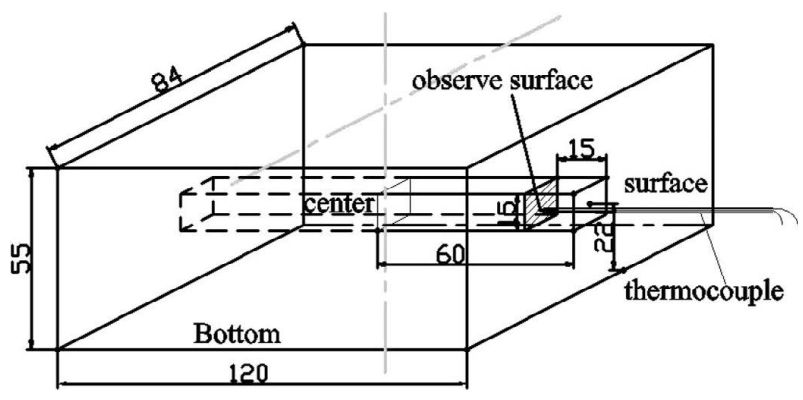

Fig. 2. Schematic view of ingot and cutting position of sample for microstructure observation.

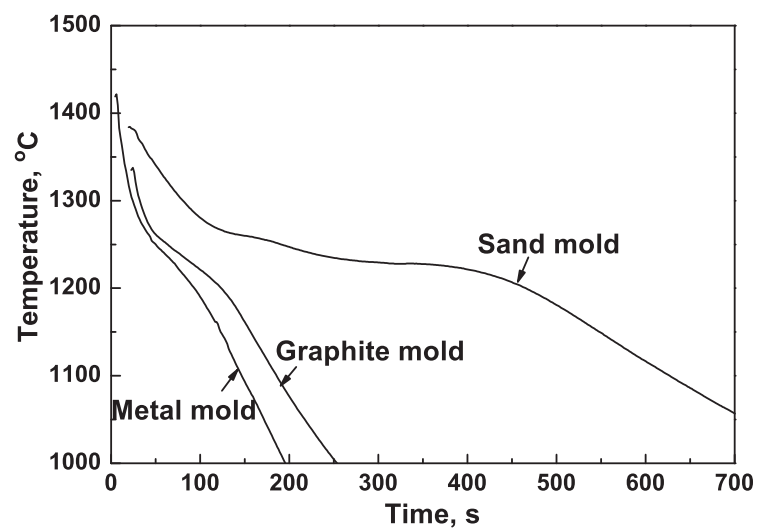

Fig. 3. Typical cooling curves measured in three kinds of molds for hypereutectic HCCIs with 1.5 mass\% Ti addition. Cooling rate condition: Sand mold: $25^{\circ} \mathrm{C} / \mathrm{min}$, graphite mold: $80^{\circ} \mathrm{C} / \mathrm{min}$ and metal mold: $110^{\circ} \mathrm{C} / \mathrm{min}$.

mold at $1450 \pm 10^{\circ} \mathrm{C}$. The following three mold types were used: sand mold (silica sand), graphite mold, metal mold (ASTM: 1045). The schematic diagram of melting process is shown in Figs. 1(a), 1(b) and 1(c).

The dimension of the ingot is $120 \mathrm{~mm} \mathrm{~L} \times 84 \mathrm{~mm}$ $\mathrm{W} \times 55 \mathrm{~mm} \mathrm{H}$. A schematic view of the ingot and the thermocouple (Type-B) position is shown in Fig. 2. In addition, the cooling curves obtained from the three different molds are shown in Fig. 3. From this information the following different cooling rates were obtained: $25^{\circ} \mathrm{C} / \mathrm{min}, 80^{\circ} \mathrm{C} / \mathrm{min}$ and $110^{\circ} \mathrm{C} / \mathrm{min}$ within $10 \%$ errors for the sand mold, graphite mold and metal mold, respectively.

\subsection{Observation of Microstructure and Carbides}

The ingot samples were cut at a position close to the 
thermocouple measurement position, as shown in Fig. 2. Thereafter, the samples were polished and etched by using a solution of $5 \mathrm{~g} \mathrm{FeCl}_{3}+10 \mathrm{ml} \mathrm{HCl}+100 \mathrm{ml}$ ethanol. Then, the size distribution of carbides was measured on photographs obtained by using a light optical microscope (LOM) (Leica DMR) at a $\times 10$ magnification, where one pixel represented $0.3356 \mu \mathrm{m}$. Furthermore, by using the back scattered electron (BSE) setting in the scanning electron microscopy (SEM) (Hitachi: S-3700N) at $\times 600$ magnifications, where one pixel represented $0.1656 \mu \mathrm{m}$. The composition of carbides including $\mathrm{Fe}, \mathrm{Cr}, \mathrm{Ti}, \mathrm{Mo}, \mathrm{Mn}$ and other elements were determined with the Energy Dispersive X-ray spectrometer (EDX) method.

The number of carbides per unit area, $\mathrm{N}_{\mathrm{A}}$, was calculated using Eq. (1).

$$
\mathrm{N}_{\mathrm{A}(\mathrm{i})}=\mathrm{n}_{(\mathrm{i})} / \mathrm{S}_{\mathrm{obs}},
$$

where $\mathrm{n}_{(\mathrm{i})}$ is the counted number of carbides for each selected step (i) of size distribution. Moreover, $\mathrm{S}_{\mathrm{obs}}$ is total area which was observed on the photographs, which were taken by LOM $\left(\mathrm{S}_{\mathrm{obs}}=0.3152 \mathrm{~mm}^{2}\right)$ and SEM $\left(\mathrm{S}_{\mathrm{obs}}=0.0314 \mathrm{~mm}^{2}\right)$, respectively. The size of carbides, $\mathrm{d}$, and the volume fraction of carbides were calculated as the equivalent diameter of a circle by using an image analyzer, which is a commercial software, WinROOF.

\subsection{Measurement of Hardness and Wear Loss}

The mechanical properties: bulk hardness and wear loss of the hypereutectic HCCIs was investigated in the as-cast condition. The bulk hardness was measured by using a Rockwell type hardness tester, HR-150A with the Rockwell $\mathrm{C}$ scale (HRC). Overall, eight measurements were done for each sample.

The wear resistance was evaluated by using a single platform rotary abraser (model: ML-100 type, Zhangjiakou Taihua Machine Factory). The wear tests were performed at a platform speed of $60 \mathrm{rpm}$ under a load of $100 \mathrm{~N}$. The size of the wear test samples was $4.1 \mathrm{~mm}(\phi) \times 10 \mathrm{~mm}(\mathrm{H})$. The tests were performed on a 80 mesh $\mathrm{Al}_{2} \mathrm{O}_{3}$ abrasive paper at room temperature. The total sliding distance and the testing time of the samples on the abrasive paper were $9 \mathrm{~m}$ and $25 \mathrm{~s}$, respectively. The mass loss of the specimens due to abrasion was calculated by measuring the weight of the specimens before and after tests with a $0.001 \mathrm{mg}$ accuracy. Three measurements were carried out per sample.

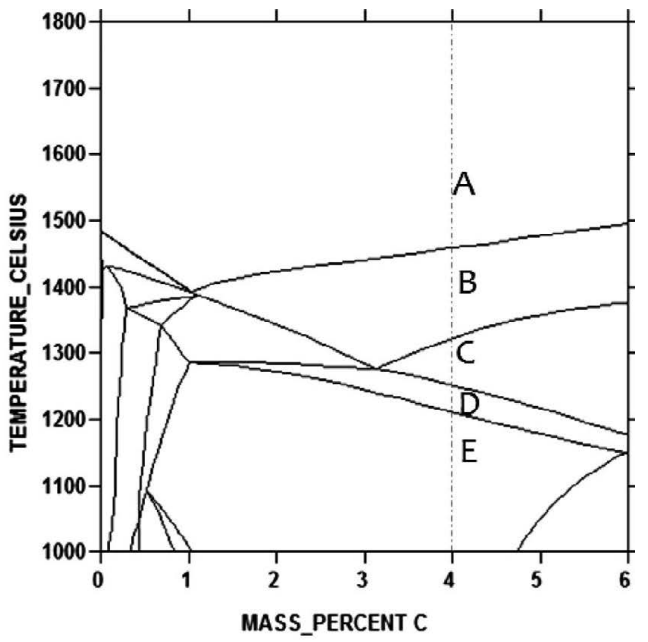

(b)

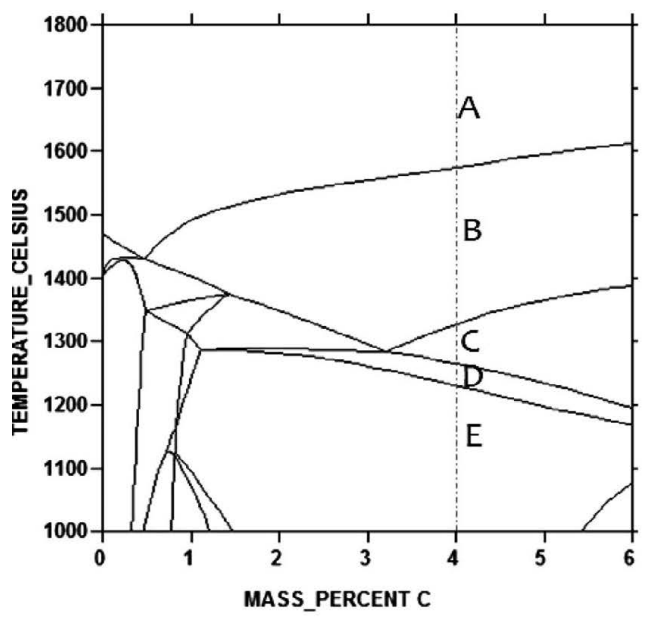

(c)

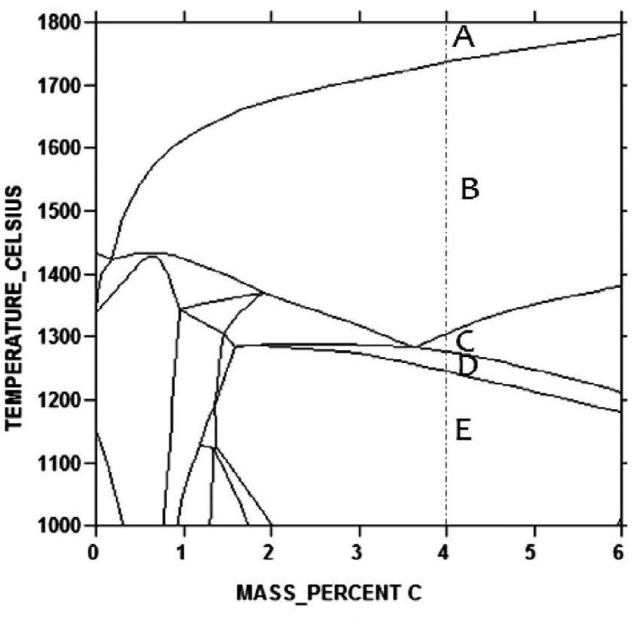

(d)

Fig. 4. Phase diagram of the hypereutectic HCCIs with (a): 0 mass $\%$, (b): 0.75 mass $\%$, (c): 1.5 mass $\%$ and (d): 3.0 mass $\%$ Ti addition by using Thermo- Calc calculations. A zone: LIQUID; B zone: LIQUID+ TiC (FCC_A1\#2); C zone: LIQUID $+\mathrm{M}_{7} \mathrm{C}_{3}$; D zone: LIQUID $+\gamma(\mathrm{FCC} \mathrm{A} 1)+\mathrm{TiC}(\mathrm{FCC} \mathrm{A} 1 \# 2)+\mathrm{M}_{7} \mathrm{C}_{3}$; E zone: $\gamma(\mathrm{FCC} \mathrm{A} 1)+\overline{\mathrm{M}}_{7} \mathrm{C}_{3}$. 


\subsection{Theoretical Works}

In this study, the phase diagram and volume fraction of carbides in HCCIs were calculated by the PE and Scheil models, which are based on the ideas of Chen and Sundman. ${ }^{10,11)}$ They are performed in the Thermo-Calc/TQ interface ${ }^{12)}$ by a coupling of thermodynamic equilibrium calculations with the alloy database TCFE6. ${ }^{13)}$

\section{Results and Discussion}

The precipitation possibilities of carbides in the hypereutectic HCCIs before and during solidification can be estimated for the sample composition given in Table 1. This can be done by thermodynamic equilibrium calculations by using the Thermo-Calc program. ${ }^{12,13)}$ The phase diagrams of the hypereutectic HCCIs with different Ti content are shown in Figs. 4(a), 4(b), 4(c) and 4(d). First, a comparison between calculation results (Fig. 4(c)) and experiment results (Fig. 3) in sand, graphite and metal molds was done for the hypereutectic HCCIs with a 1.5 mass\% Ti addition. From this comparison, it was found that in all three mold types, the actual precipitation temperatures of primary $\mathrm{M}_{7} \mathrm{C}_{3}$ carbides were not clear during these trials. However, it was seen that the actual precipitation temperatures of austenite $(\gamma)$ were a little bit lower than the equilibrium temperature $1258^{\circ} \mathrm{C}$. The actual precipitation temperature of austenite $(\gamma)$ is clear in the sand mold.

It was also found that the solidification was initiated with a formation of primary $\mathrm{M}_{7} \mathrm{C}_{3}$ carbides, which began to precipitate at $1337^{\circ} \mathrm{C}$, Thereafter, the eutectic reaction $\mathrm{L} \rightarrow$
$\gamma+\mathrm{M}_{7} \mathrm{C}_{3}$ took place during the cooling from $1256^{\circ} \mathrm{C}$ to $1215^{\circ} \mathrm{C}$. This is valid for the case without Ti additions, as illustrated in Fig. 4(a). On the other hand, in the case with a Ti addition, the precipitation sequence is changed as shown in Figs. 4(b), 4(c) and 4(d). In the case with a 1.5 mass $\%$ Ti addition, $\mathrm{FCC} \mathrm{Al} \# 2$ (corresponds to the $\mathrm{NaCl}$ type carbides such as $\mathrm{TiC}$ carbide) first precipitates at $1549^{\circ} \mathrm{C}$. Then, the primary $\mathrm{M}_{7} \mathrm{C}_{3}$ carbides precipitate at $1317^{\circ} \mathrm{C}$. Finally, the eutectic reaction $\mathrm{L} \rightarrow \gamma+\mathrm{M}_{7} \mathrm{C}_{3}$ occur from $1258^{\circ} \mathrm{C}$. Moreover, the precipitation temperature of the $\mathrm{TiC}$ carbide increases from $1459^{\circ} \mathrm{C}$ to $1734^{\circ} \mathrm{C}$ with an increased Ti content from 0.75 mass $\%$ to 3.0 mass $\%$.

\subsection{Effect of Cooling Rate on Solidification Structure}

Effect of cooling rates, which were examined in the three kinds of mold, on the microstructure evolution is discussed in this section. In Figs. 5(a) and 5(b), micrographs and binary images of the hypereutectic HCCIs under different cooling rates for the cases without $\mathrm{Ti}$ additions and with 1.5 mass $\%$ Ti additions are shown. The microstructure consists of primary $\mathrm{M}_{7} \mathrm{C}_{3}$ carbides with a large hexagonal columnar structure, eutectic $\mathrm{M}_{7} \mathrm{C}_{3}$ carbides with an irregular shape, TiC carbides with a cubic structure and a matrix containing mainly of an austenite phase $(\gamma)$. It is apparent from the photographs in Fig. 5(a) that in the case without Ti addition, the size of primary $\mathrm{M}_{7} \mathrm{C}_{3}$ carbides decreases as the cooling rate increase. It is also apparent from the comparison between Figs. 5(a) and 5(b) that the size of $\mathrm{M}_{7} \mathrm{C}_{3}$ carbides in the case of a 1.5 mass $\%$ Ti addition is significantly smaller than that in the case without a Ti addition. This is

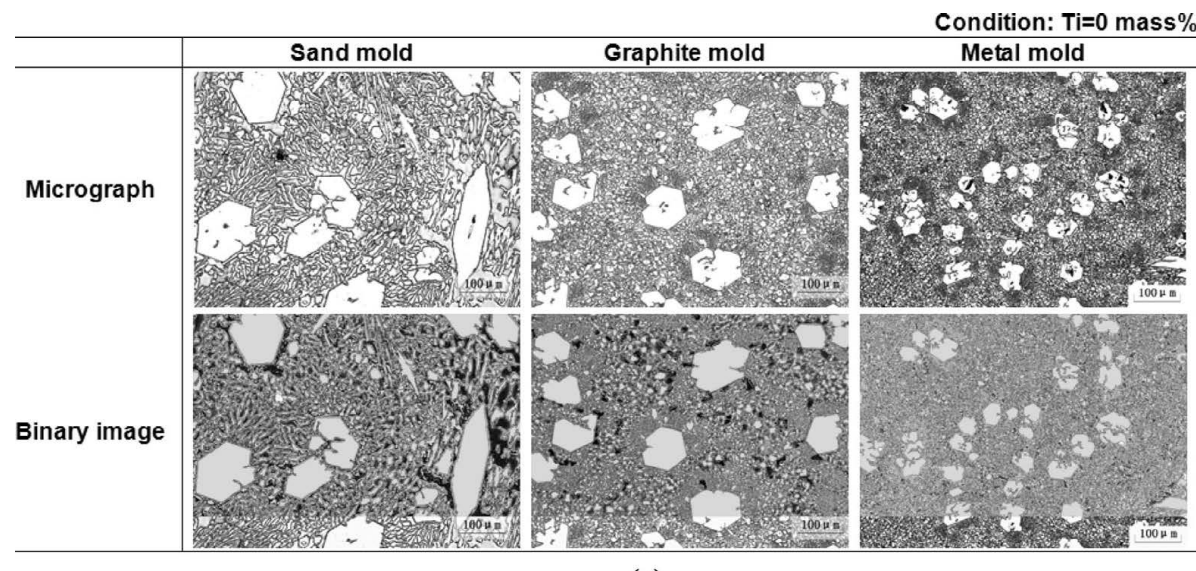

(a)

Condition: $\mathrm{Ti}=\mathbf{1} .5$ mass $\%$

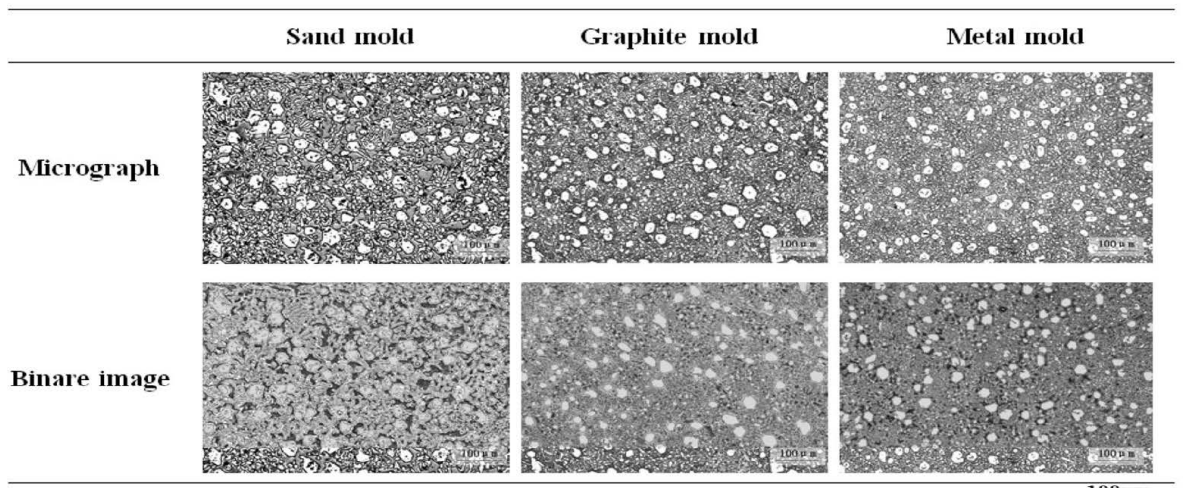

(b)

Fig. 5. Optical Microscope Observations for $\mathrm{M}_{7} \mathrm{C}_{3}$ carbide under different cooling rate, (a) $\mathrm{Ti}=0$ mass $\%$, (b) $\mathrm{Ti}=1.5 \mathrm{mass} \%$. 
due to a precipitation of $\mathrm{TiC}$ carbides. The size determination of $\mathrm{M}_{7} \mathrm{C}_{3}$ carbides were measured for different cooling rates using an image analyzer (WinROOF) both for the cases without a $\mathrm{Ti}$ addition and with a 1.5 mass $\%$ Ti addition. In Figs. 6(a) and 6(b), the size distributions are plotted using a logarithmic scale. The value of size $d_{(j)}$, for the $j$-th step, $\Delta_{(\mathrm{j})}$, of a log-normal distribution can be determined as follows:

$$
\mathrm{d}_{(\mathrm{j})}=10^{\Delta}(\mathrm{j})
$$

where $\Delta_{(\mathrm{j})}$ is the width of the j-th step for log-normal distributions $\left(\Delta_{(j)}=\Delta_{(j-1)}+0.15\right)$. This range is from -0.15 to 2.4 In this case, the mean value of the $\mathrm{M}_{7} \mathrm{C}_{3}$ carbides size for the $\mathrm{j}$-th step of the size distribution, $\mathrm{d}_{(\mathrm{j})}$, varies from 0.85 to $214.51 \mu \mathrm{m}$. It can be seen that the size distributions of $\mathrm{M}_{7} \mathrm{C}_{3}$ carbides show a log-normal distribution for the cases in Fig. 6(a) without a Ti addition and in Fig. 6(b) with a 1.5 mass $\%$ Ti addition, respectively.
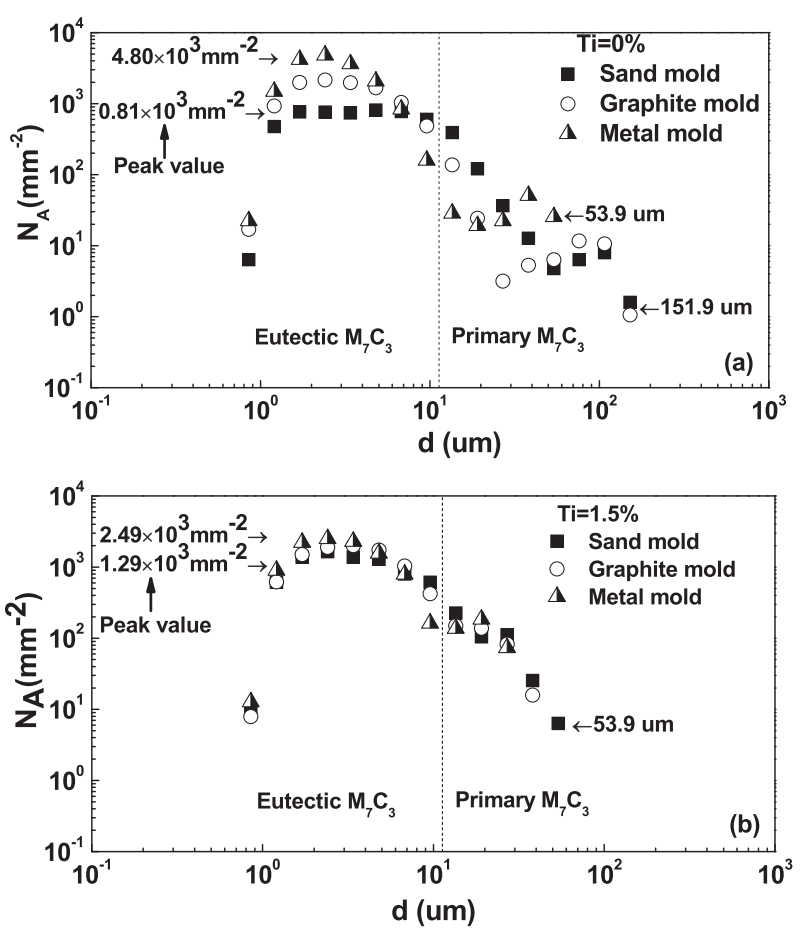

Fig. 6. Effect of cooling rate on $\mathrm{M}_{7} \mathrm{C}_{3}$ carbide size distribution of the hypereutectic HCCIs with (a): without Ti addition; (b): 1.5 mass $\%$ Ti addition by using optical microscope photos.
As shown in Fig. 6(a) representing a case without Ti additions, the maximum size of primary $\mathrm{M}_{7} \mathrm{C}_{3}$ carbides $(>11.2 \mu \mathrm{m})$ decreases from 151.9 to $53.9 \mu \mathrm{m}$ with an increased cooling rate (from a sand mold to a metal mold). In addition, the number of eutectic $\mathrm{M}_{7} \mathrm{C}_{3}$ carbides, which in general has a size less than $11.2 \mu \mathrm{m}$, increases from $0.81 \times 10^{3} \mathrm{~mm}^{-2}$ to $4.80 \times 10^{3} \mathrm{~mm}^{-2}$ with an increased cooling rate. Moreover, as shown in Fig. 6(b) representing a case with a 1.5 mass\% $\%$ Ti addition, the maximum size of primary $\mathrm{M}_{7} \mathrm{C}_{3}$ carbides $(>11.2 \mu \mathrm{m})$ is not changed too a large degree. However, the number of eutectic $\mathrm{M}_{7} \mathrm{C}_{3}$ carbides $(<11.2 \mu \mathrm{m})$ increases from $1.29 \times 10^{3} \mathrm{~mm}^{-2}$ to $2.49 \times 10^{3} \mathrm{~mm}^{-2}$ with an increased cooling rate when a 1.5 mass $\%$ Ti addition is used. This border value of " $11.2 \mu \mathrm{m}$ " in the classification of $\mathrm{M}_{7} \mathrm{C}_{3}$ will be explained in detail in Section 3.2.2.

Comparing Figs. 6(a) with 6(b), it can be seen that the size of primary $\mathrm{M}_{7} \mathrm{C}_{3}$ carbides in the case of a 1.5 mass $\% \mathrm{Ti}$ addition is significantly smaller than that in the case without a $\mathrm{Ti}$ addition. Furthermore, that the maximum sizes are $53.9 \mu \mathrm{m}$ and $151.9 \mu \mathrm{m}$ respectively. This can be explained by the precipitation of $\mathrm{TiC}$ carbide in the melt, as is discussed in section 3.2.3.

If the cooling rate is increased, the nucleation probability of primary $\mathrm{M}_{7} \mathrm{C}_{3}$ carbides increases due to the increase of the precipitation undercooling degree. Under low cooling rates, the primary $\mathrm{M}_{7} \mathrm{C}_{3}$ carbides grow larger and coarser, because the growth time becomes longer. Therefore, with the increase of the cooling rate the size of primary $\mathrm{M}_{7} \mathrm{C}_{3}$ carbides will decrease and they will be distributed relatively uniformly. In addition, the number of primary $\mathrm{M}_{7} \mathrm{C}_{3}$ carbides will increase at high nucleation rates.

From the above discussion, it was found that the size of primary $\mathrm{M}_{7} \mathrm{C}_{3}$ carbides of the hypereutectic HCCIs can be refined both by $\mathrm{Ti}$ additions and by increasing the cooling rate. In addition, the number of eutectic $\mathrm{M}_{7} \mathrm{C}_{3}$ carbides increase, and consequently the eutectic structure is refined by an increased cooling rate in both cases without a Ti addition and with a Ti addition.

\subsection{Effect of Ti Addition on Solidification Structure}

\subsubsection{Effect of Ti Addition on $\mathrm{M}_{7} \mathrm{C}_{3}$ Carbides Distribu-} tions and Volume Fraction

Figure 7 shows the micrographs and binary images of the solidification structure for different $\mathrm{Ti}$ additions obtained by light optical microscopy at $\times 10$ magnifications. Here, the

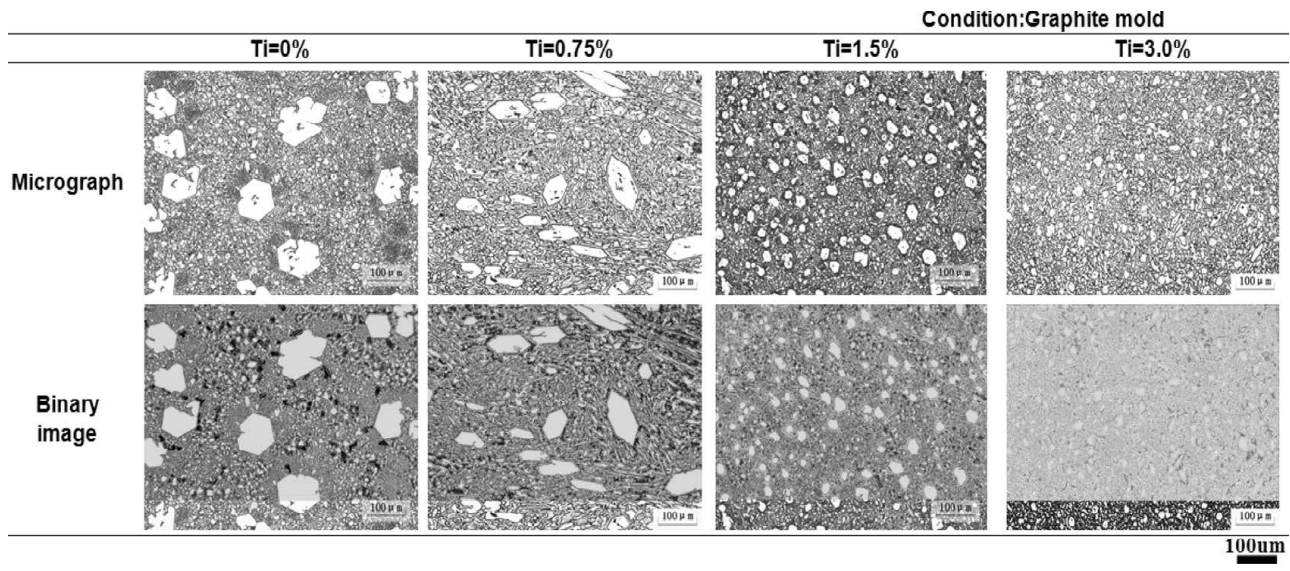

Fig. 7. Optical Microscope Observations for $\mathrm{M}_{7} \mathrm{C}_{3}$ carbide in the graphite mold. 
key point is that $\mathrm{TiC}$ carbides precipitated before the primary $\mathrm{M}_{7} \mathrm{C}_{3}$ carbides in the melt. The size distributions of $\mathrm{M}_{7} \mathrm{C}_{3}$ carbides with different $\mathrm{Ti}$ additions in the graphite mold were measured by an image analyzer, WinROOF program. The size distributions are plotted with logarithmic step in Fig. 8. The step range value of the log-normal size distribution is calculated by Eq. (2). The $\Delta$ value varies from -0.15 to 2.4 , the size, $\mathrm{d}$, is varies from 0.85 to 214.51 .

As shown in Fig. 8, the size distributions of $\mathrm{M}_{7} \mathrm{C}_{3}$ carbides also resemble a log-normal distribution. It can be seen that the maximum size of the primary $\mathrm{M}_{7} \mathrm{C}_{3}$ carbides decreases from 151.9 to $27.0 \mu \mathrm{m}$ with an increased Ti addition in the graphite mold. However, the size and number of eutectic $\mathrm{M}_{7} \mathrm{C}_{3}$ do not change too a large degree (from $2.00 \times 10^{3} \mathrm{~mm}^{-2}$ to $2.84 \times 10^{3} \mathrm{~mm}^{-2}$ ) with an increased Ti content. The reason for this will be explained in section 3.2.3.

\subsubsection{Classification of $\mathrm{M}_{7} \mathrm{C}_{3}$ Carbides}

In this study, it is suggested that the $\mathrm{M}_{7} \mathrm{C}_{3}$ type carbides in the HCCIs can be classified into primary $\mathrm{M}_{7} \mathrm{C}_{3}$ carbides and eutectic $\mathrm{M}_{7} \mathrm{C}_{3}$ carbides depending on the time of precipitation. The primary carbides precipitate in the melt before solidification (that is during cooling of the melt until the solidification temperature is reached). The eutectic $\mathrm{M}_{7} \mathrm{C}_{3}$ carbides precipitate during the eutectic reaction. The precipitation possibility of $\mathrm{M}_{7} \mathrm{C}_{3}$ carbides before and during solidification is estimated for the sample composition given in Table 1. This was done based on thermodynamic equilibrium calculations by using Thermo-Calc. The volume fraction of precipitated primary $\mathrm{M}_{7} \mathrm{C}_{3}$ carbides, eutectic $\mathrm{M}_{7} \mathrm{C}_{3}$ carbides and $\mathrm{TiC}$ carbides are plotted against the temperature in Fig. 9. It can be seen that the precipitation temperature of primary $\mathrm{M}_{7} \mathrm{C}_{3}$ carbides decreases with an increased $\mathrm{Ti}$ content. However, the precipitation temperature of $\mathrm{TiC}$ carbides increases slightly with an increased Ti content.

Figure 10 shows Thermo-Calc calculation and experiment results of total, primary and eutectic $\mathrm{M}_{7} \mathrm{C}_{3}$ carbides in the hypereutectic $\mathrm{HCCIs}$ for different Ti additions. Here, (a) $\mathrm{d}=7.9 \mu \mathrm{m}$ and (b) $\mathrm{d}=11.2 \mu \mathrm{m}$ were adopted as the $\mathrm{M}_{7} \mathrm{C}_{3}$ carbide's border size, d. Comparing Figs. 10(a) with 10(b), it can be seen that experimental results with a $11.2 \mu \mathrm{m}$ border size are closed to the calculation results from the viewpoint of the primary $\mathrm{M}_{7} \mathrm{C}_{3}$ carbides volume fraction (see $\bigcirc$ mark). Regarding eutectic $\mathrm{M}_{7} \mathrm{C}_{3}$ carbides (see $\triangle$ mark), experiment data are $5 \%$ lower than calculation curve. This might be due to the difficulty of deciding the threshold from the gray

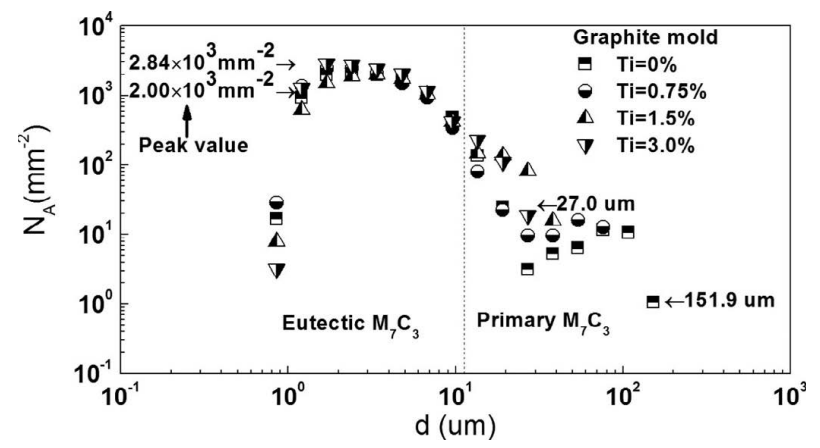

Fig. 8. Effect of Ti addition on $\mathrm{M}_{7} \mathrm{C}_{3}$ carbides size distribution of the hypereutectic HCCIs in the graphite mold obtained by using optical microscope photos. images of the optical microscope photos. Moreover, the experimental results are close to the Partial Equilibrium (PE) calculations. The difference between the experiment results and the calculation results is lower than 5\%. This can be explained by that the carbon back diffusion is taken into consideration in the PE calculation. Therefore, the results will be closer to reality. It is also found that the $\mathrm{C}$ content has a large influence on the total volume fraction of $\mathrm{M}_{7} \mathrm{C}_{3}$ carbides. More specifically, the total volume fraction increases with an increased C content, as shown in Fig. 10.

In addition, Fig. 10 shows that the total volume fraction of $\mathrm{M}_{7} \mathrm{C}_{3}$ carbides decreases as the Ti content increases; the

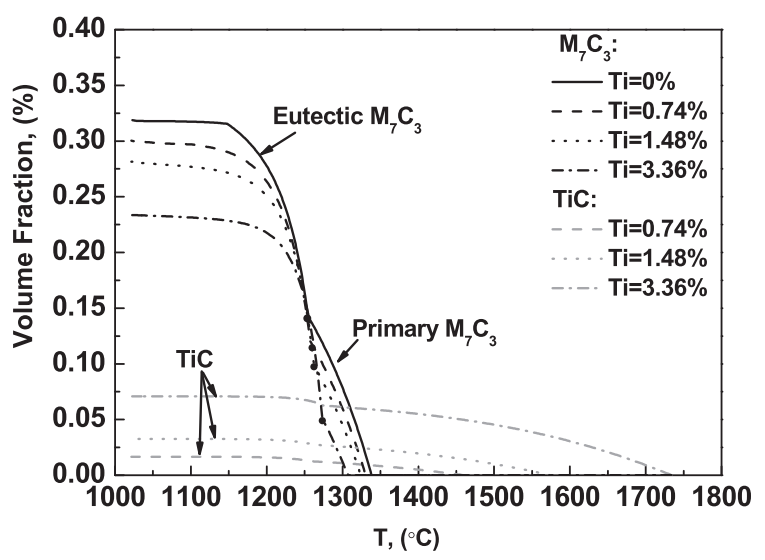

Fig. 9. Volume fraction of $\mathrm{M}_{7} \mathrm{C}_{3}$ carbide and $\mathrm{TiC}$ carbide of the hypereutectic HCCIs with different Ti additions obtained by using PE model calculation for $\mathrm{Fe}-3.98$ mass $\% \mathrm{C}-16.8$ mass $\% \mathrm{Cr}-1.86$ mass $\% \mathrm{Mn}-0.943$ mass $\% \mathrm{Mo}-1.09$ mass $\% \mathrm{Ni}-$ 0.970 mass \% Si. "•": transformation points of $\mathrm{M}_{7} \mathrm{C}_{3}$ carbide.
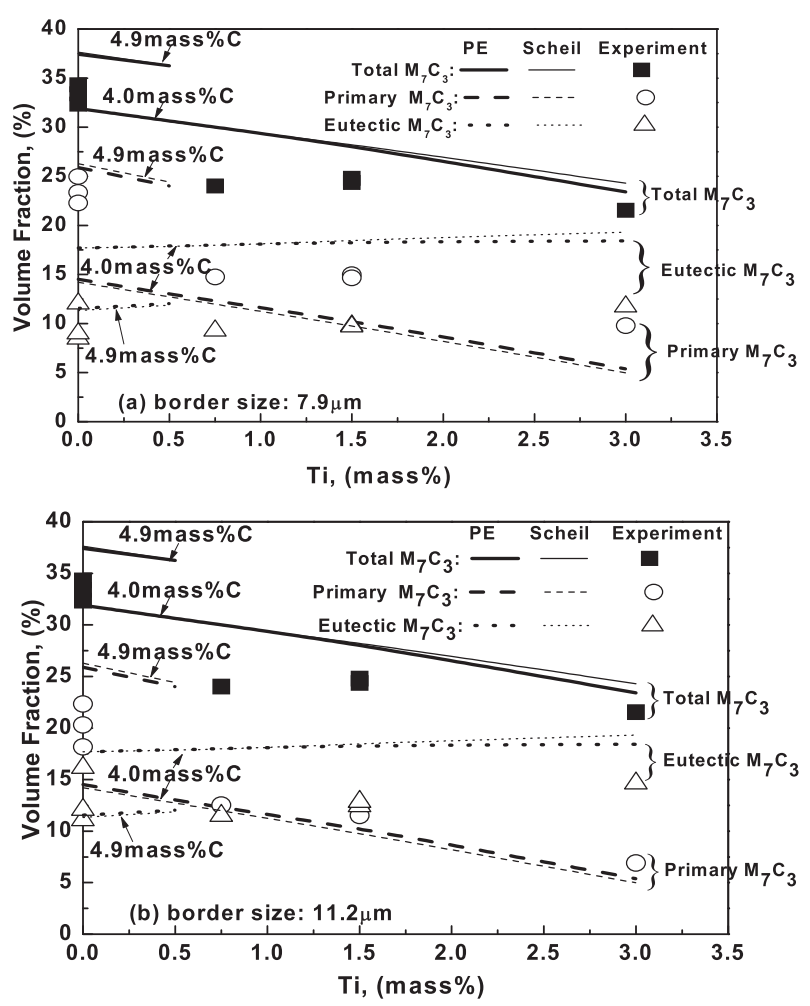

Fig. 10. Thermo-Calc calculation and experimental results of total, primary and eutectic $\mathrm{M}_{7} \mathrm{C}_{3}$ carbides in the hypereutectic HCCIs with different Ti additions. $\mathrm{M}_{7} \mathrm{C}_{3}$ carbide's border size: (a) $\mathrm{d}=7.9 \mu \mathrm{m}$, (b) $\mathrm{d}=11.2 \mu \mathrm{m}$. 
volume fraction of primary $\mathrm{M}_{7} \mathrm{C}_{3}$ carbides decreases with an increased Ti content. However, the volume fraction of eutectic $\mathrm{M}_{7} \mathrm{C}_{3}$ carbides increases with an increased Ti content.

The contents of $\mathrm{Fe}, \mathrm{Cr}$, Ti, Mo, $\mathrm{Mn}$ in primary $\mathrm{M}_{7} \mathrm{C}_{3}$ carbides and eutectic $\mathrm{M}_{7} \mathrm{C}_{3}$ carbides are plotted against the carbide sizes in Fig. 11 for the sand, graphite and metal molds for a 1.5 mass $\% \mathrm{Ti}$ addition. As a general characteristic, it is shown that the content of $\mathrm{Cr}$ and $\mathrm{Ti}$ increases with an increased $\mathrm{M}_{7} \mathrm{C}_{3}$ carbide size, $\mathrm{d}$. However, the content of $\mathrm{Fe}$ and Mo decreases with an increased $\mathrm{M}_{7} \mathrm{C}_{3}$ carbide size; Moreover, the content of $\mathrm{Mn}$ does not change with an increased $\mathrm{M}_{7} \mathrm{C}_{3}$ carbide size for the sand, graphite and metal molds. It is concluded that the primary $\mathrm{M}_{7} \mathrm{C}_{3}$ carbides are dominant at higher $\mathrm{Cr}$ contents, and that the eutectic $\mathrm{M}_{7} \mathrm{C}_{3}$ carbides have a lower $\mathrm{Cr}$ contents.

Based on the analysis of size distribution and composi-
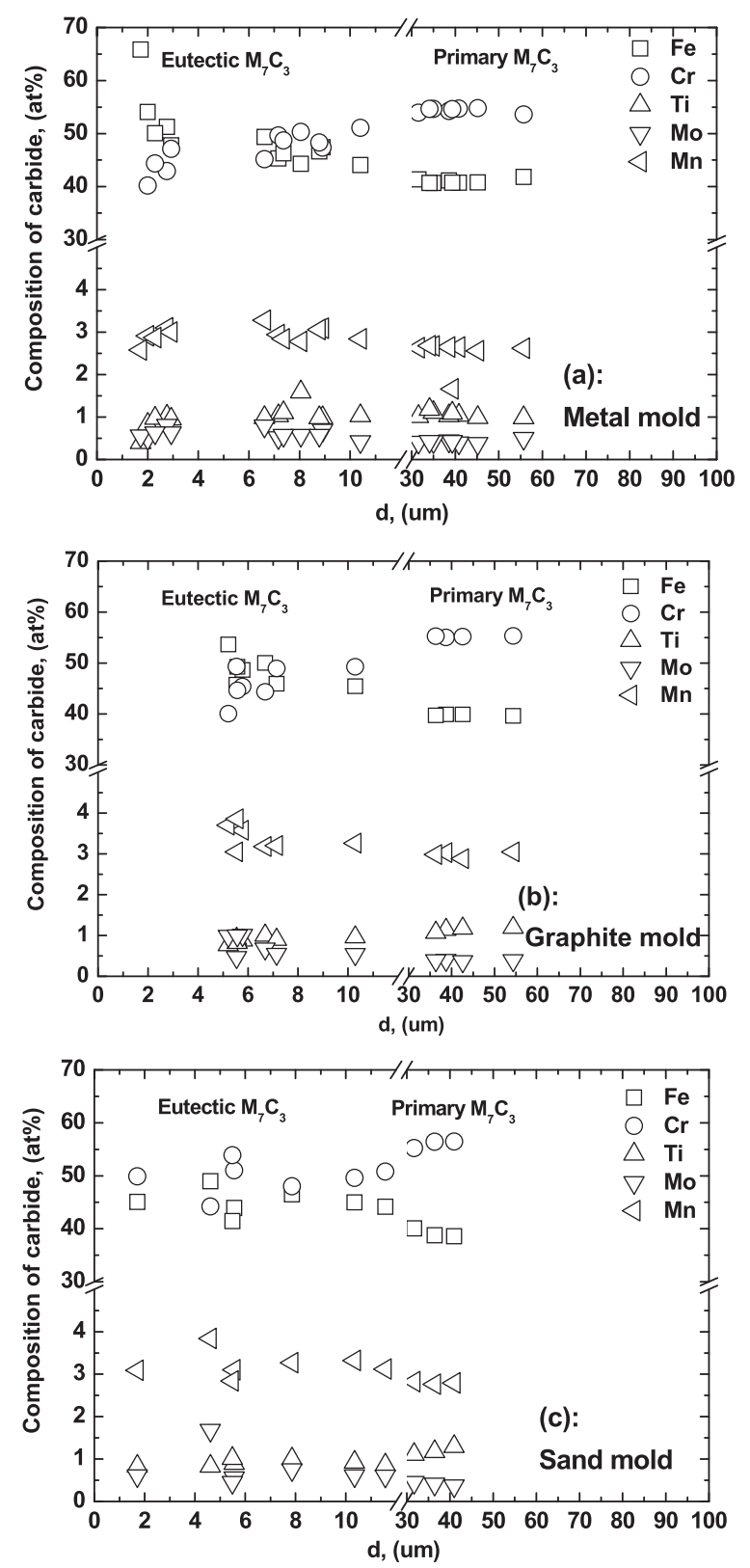

Fig. 11. Relationship between composition and size of primary $\mathrm{M}_{7} \mathrm{C}_{3}$ carbides and eutectic $\mathrm{M}_{7} \mathrm{C}_{3}$ carbides of the hypereutectic HCCIs with 1.5 mass\% $\%$ i addition under different cooling rates: (a) Metal mold, (b) Graphite mold, (c) Sand mold. tion, the $\mathrm{M}_{7} \mathrm{C}_{3}$ carbides were roughly classified into primary $\mathrm{M}_{7} \mathrm{C}_{3}$ carbides, which in general have size larger than $11.2 \mu \mathrm{m}$. Moreover, into eutectic $\mathrm{M}_{7} \mathrm{C}_{3}$ carbides which in general have a size smaller than $11.2 \mu \mathrm{m}$.

\subsubsection{Detail Analysis for Ti Carbides}

From the phase diagrams and the carbide precipitation temperature of carbide of the hypereutectic HCCIs with different Ti addition are shown in Figs. 4 and 9 respectively. It can be seen that $\mathrm{TiC}$ carbides with a $\mathrm{NaCl}$ type structure will precipitate at high temperatures in the melt. The formation temperature of $\mathrm{TiC}$ carbides is close to $1740^{\circ} \mathrm{C}$, when the Ti content is 3.0 mass $\%$. TiC carbides are the first precipitated phase and they play an important role in refining and reinforcing the microstructure of the hypereutectic HCCIs. This is due to that they can act as heterogeneous nuclei in the $\mathrm{M}_{7} \mathrm{C}_{3}$ carbides $^{2-4}$ ) formations. In addition, it was also found that the holding time of the melt is very important for the TiC carbide formation in order to refine the solidification structure. This is due to the high formation temperature of TiC carbides. The effect of the holding time on the microstructure of the hypereutectic HCCIs during heating and holding at high temperature will be considered in the future. In this study, the holding time over the $\mathrm{TiC}$ precipitation temperature was controlled as $3 \mathrm{~min} \pm 1 \mathrm{~min}$, in order to prevent the scattering of $\mathrm{TiC}$ carbides precipitation and agglomeration.

The back scattered electron (BSE) observations for TiC carbides are shown in Fig. 12. It is confirmed that the TiC carbides can act as a nuclei of $\mathrm{M}_{7} \mathrm{C}_{3}$ carbides. More specifically, they are mostly located inside or at the boundary of $\mathrm{M}_{7} \mathrm{C}_{3}$ carbides, as shown in Fig. 12. Moreover, TiC carbides starts to grow and agglomerate when the $\mathrm{Ti}$ content is 1.5 mass\%, as shown in Fig. 12(b). It is also apparent from the photographs in Fig. 12(c) that larger and coarser clusters of $\mathrm{TiC}$ carbides exist.

The size distributions of $\mathrm{TiC}$ carbides of the hypereutectic HCCIs with different Ti addition under three kinds of mold were measured by using an image analyzer, WinROOF program. These data are shown in Figs. 13 and 14 using a logarithmic scale. The range value $\Delta$ of size of the log-normal distribution is calculated by Eq. (2). The value of $\Delta$ between -1.05 to 2.1 and the value of $\mathrm{d}$ are between 0.11 to $107.51 \mu \mathrm{m}$.

The size distribution of TiC carbides in the graphite mold with different Ti addition is shown in Fig. 13. These carbides generally have a size less than $10 \mu \mathrm{m}$. Moreover, it can be seen that both the size and number of TiC carbides increase with an increased Ti addition. Also, Fig. 14 shows the size distribution of $\mathrm{TiC}$ carbides with a 1.5 mass $\% \mathrm{Ti}$ addition in sand mold, graphite mold and metal mold. The average size of $\mathrm{TiC}$ carbides with a 1.5 mass $\%$ Ti addition does not change practically with an increased cooling rate. Also, the number of $\mathrm{TiC}$ carbides does not change due to the increased cooling rate. Consequently, it is clear that the precipitation of TiC carbides was not seemingly affected by the cooling rate. Thus, it is confirmed that the cooling rate will not affect the precipitation behavior of TiC carbides.

The back scattered electron micrograph results at a high magnification $(\times 2500)$ of the hypereutectic HCCIs with 1.5 mass \% Ti addition is shown in Fig. 15. It was found that 

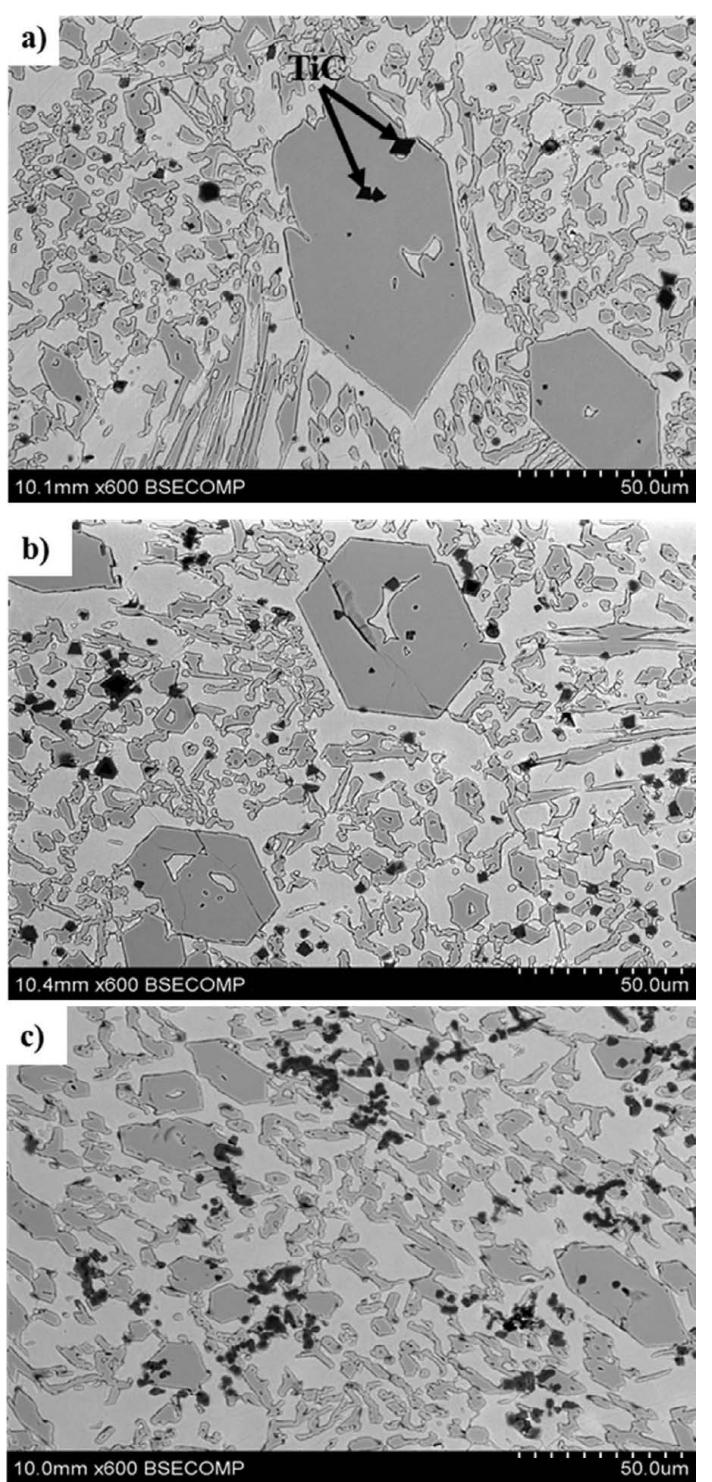

Fig. 12. SEM observation for $\mathrm{TiC}$ carbide, (a): $\mathrm{Ti}=0.75$ mass $\%$, (b): $\mathrm{Ti}=1.5$ mass $\%$, (c): $\mathrm{Ti}=3.0$ mass $\%$.

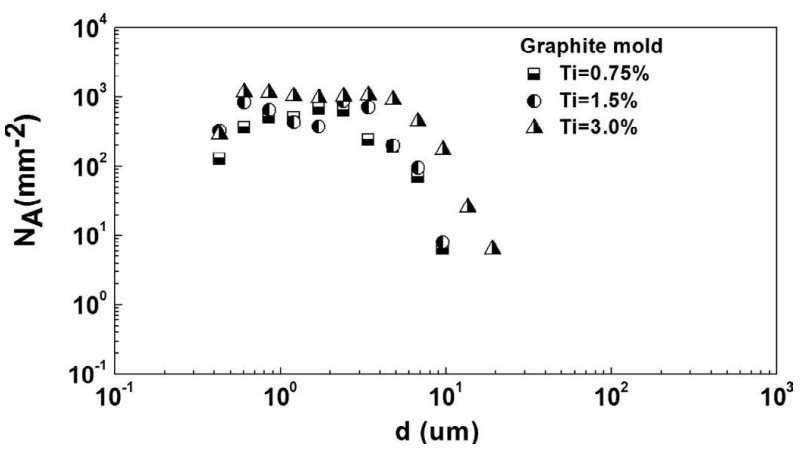

Fig. 13. Effect of Ti addition on $\mathrm{TiC}$ carbide size distribution of the hypereutectic HCCIs in the graphite obtained by using SEM photos.

TiC carbides can not only act as nuclei of $\mathrm{M}_{7} \mathrm{C}_{3}$ carbides, but they also contain a $\mathrm{Ti}(\mathrm{C}, \mathrm{N})$ core. See black point $\mathrm{A}, \mathrm{C}$ in Fig. 15. Furthermore, the chemical compositions of these carbides were examined by EDX in the SEM. As shown in Fig. 16, the main composition particle in $\mathrm{B}$ and $\mathrm{D}$ is Ti, Mo and $\mathrm{C}$. The results show that the $\mathrm{TiC}$ carbides are $(\mathrm{Ti}, \mathrm{Mo}) \mathrm{C}$.

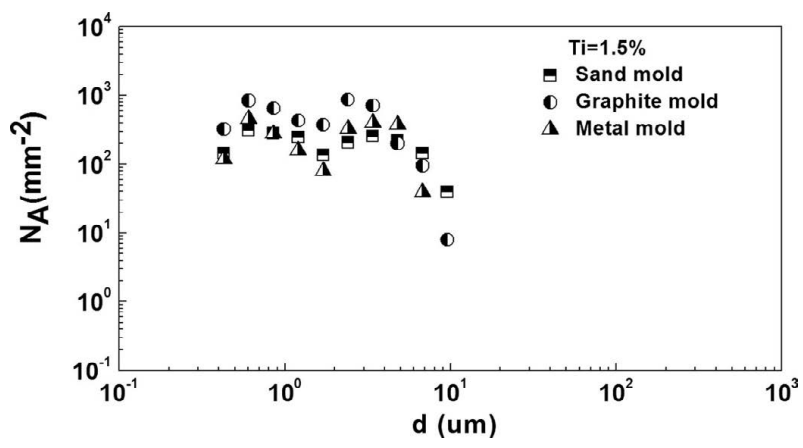

Fig. 14. Effect of cooling rate on $\mathrm{TiC}$ carbide size distribution of the hypereutectic HCCIs with 1.5 mass $\%$ Ti addition obtained by using SEM photos.

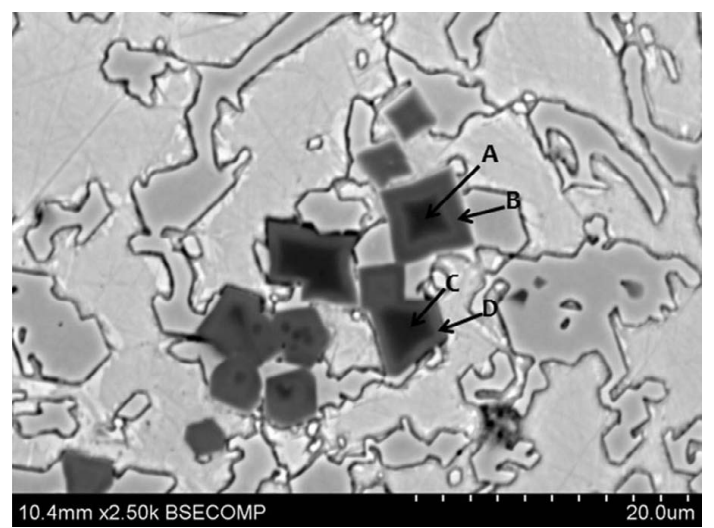

Fig. 15. SEM observation for $\mathrm{TiC}$ carbide with a $1.5 \mathrm{mass} \% \mathrm{Ti}$ addition in the graphite mold. (Point $\mathrm{A}$ : Ti(C,N); Point B: (Ti,Mo)C; Point C: Ti(C,N); Point D: (Ti,Mo)C;).

However the chemical composition of the black points $\mathrm{A}$ and $\mathrm{C}$ shows that $\mathrm{Ti}, \mathrm{C}$ and $\mathrm{N}$ are dominant, and that the TiC carbides should be $\mathrm{Ti}(\mathrm{C}, \mathrm{N})$.

Meanwhile, it can be seen from the TiC carbides size distribution that two peaks exist, as shown in Fig. 14. Based on the EDX results, it seems that the left peak corresponds to $\mathrm{Ti}(\mathrm{C}, \mathrm{N})$ and the right peak corresponds to $(\mathrm{Ti}, \mathrm{Mo}) \mathrm{C}$, as shown in Fig. 16. It can be seen that the number of $\operatorname{Ti}(\mathrm{C}, \mathrm{N})$ and $(\mathrm{Ti}, \mathrm{Mo}) \mathrm{C}$ are the same. However, the size of $(\mathrm{Ti}, \mathrm{Mo}) \mathrm{C}$ is larger than the size of $\mathrm{Ti}(\mathrm{C}, \mathrm{N})$. Therefore, it may be deduced from the EDX results that $\operatorname{Ti}(\mathrm{C}, \mathrm{N})$ can act as nuclei for (Ti, Mo)C.

Calculation results and experiment results of the volume fractions of $\mathrm{M}_{7} \mathrm{C}_{3}$ carbides and TiC carbides are shown in Fig. 17. It can be seen that the volume fraction of $M_{7} C_{3}$ carbides decreases with an increased cooling rate. The condition in the low cooling rate seems to be more close to the condition in the equilibrium state. However, the 5-10 vol. \% of $\mathrm{M}_{7} \mathrm{C}_{3}$ carbides did not fully precipitate in the high cooling rate condition. Moreover, the volume fraction of $\mathrm{M}_{7} \mathrm{C}_{3}$ carbides decreases with a $\mathrm{Ti}$ addition due to the $\mathrm{C}$ reaction by Ti. Furthermore, the volume fraction of Ti carbides increases with increased Ti additions in the graphite mold. However, the volume fraction of $\mathrm{TiC}$ carbides does not change although the cooling rate changed.

If the experiment results are compared to the calculation results, it can be seen that the tendency is the same, and that the experimental results are more close to the PE calculation results. The agreement between experiment and calculation 

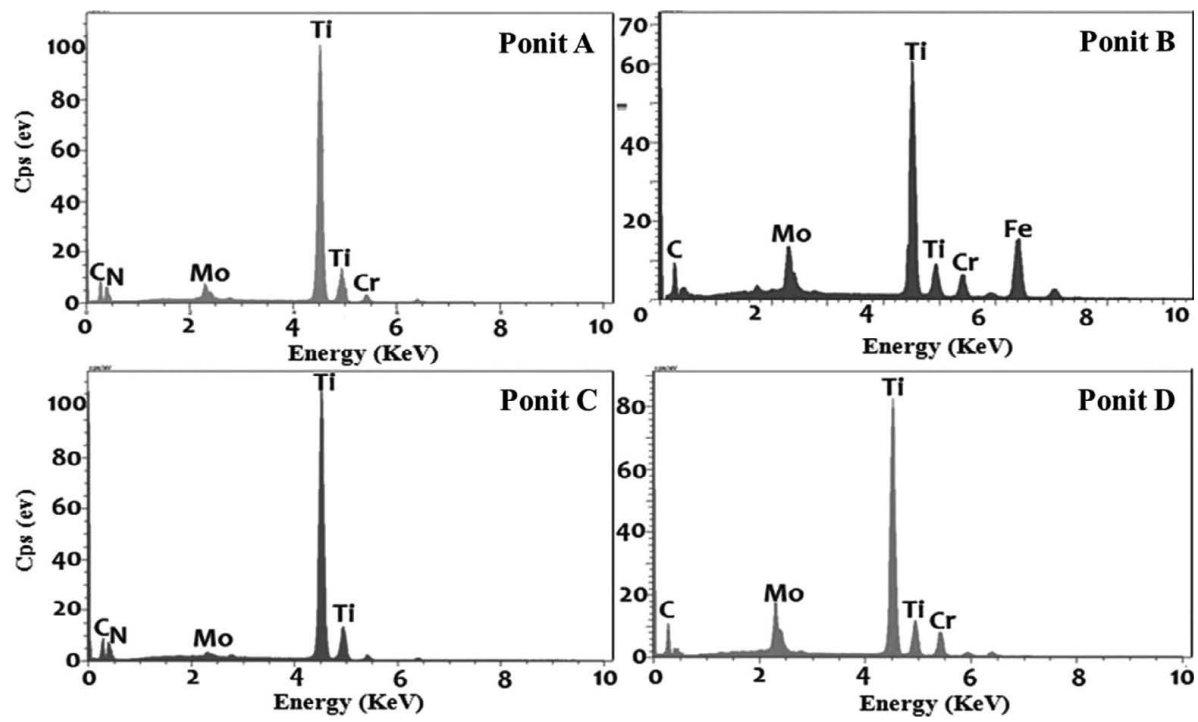

Fig. 16. EDX for TiC carbide with 1.5 mass $\%$ Ti addition in the graphite mold.

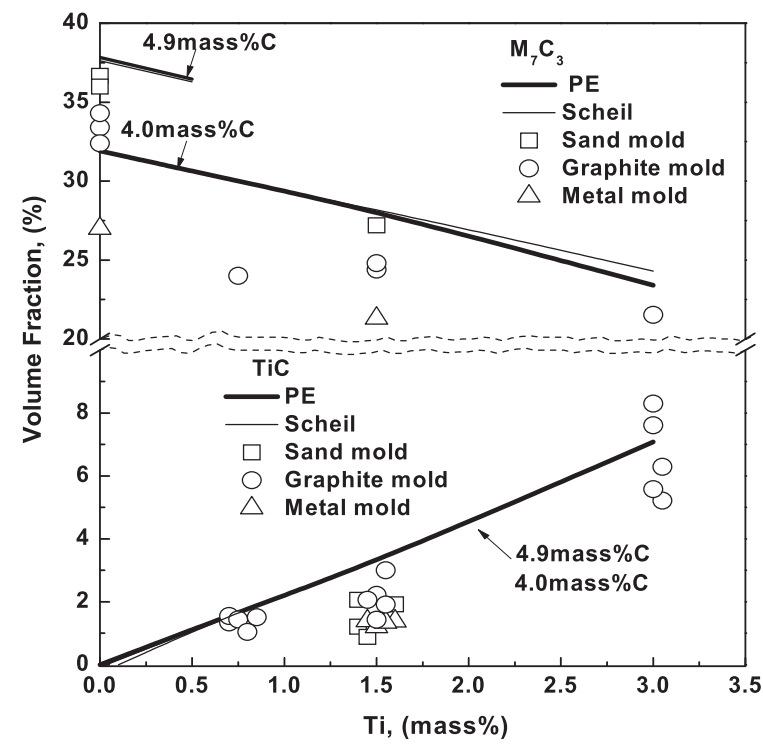

Fig. 17. Calculation results and experiment results on volume fraction of $\mathrm{M}_{7} \mathrm{C}_{3}$ carbides and $\mathrm{TiC}$ carbide.

results within $5 \%$ is encouraging. This is due to that the PE calculation considers the carbon back diffusion and consequently the results will be closer to reality.

\subsection{Effect of Cooling Rate and Ti Addition on the Mechanical Properties in As-cast Condition of the Hypereutectic HCCIs}

The bulk hardness of the hypereutectic HCCIs is determined by the hardness of carbides, such as $\mathrm{TiC}$ and $\mathrm{M}_{7} \mathrm{C}_{3}{ }^{14}$ ) and the matrix. The matrix of the hypereutectic HCCIs will obviously not change by a Ti addition. This is due to that it will mainly exist as a single austenite phase ( $\gamma$-phase) together with small amounts of martensite ( $\alpha$-phase) under as-cast conditions. Therefore, the bulk hardness of the hypereutectic HCCIs is mainly affected by the volume fraction of carbides.

The effect of cooling rate and $\mathrm{Ti}$ addition on the mechanical properties of the hypereutectic HCCIs will be discussed, but only for as-cast conditions. Figure 18 shows the bulk

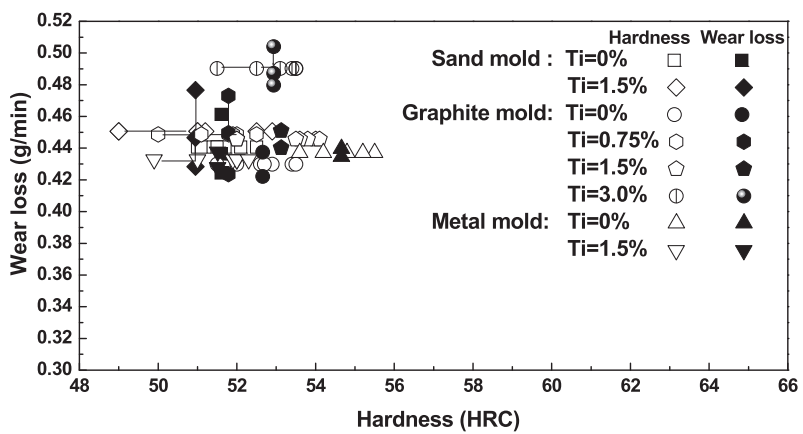

Fig. 18. Mechanical properties of the hypereutectic HCCIs with different $\mathrm{Ti}$ additions and different cooling rates.

hardness of the hypereutectic HCCIs with different Ti additions for different cooling rates. The tendency is that the bulk hardness increases a slightly with increased titanium contents. As shown in Fig. 17, when Ti is added, the volume fraction of $\mathrm{TiC}$ carbides increase and the volume fraction of $\mathrm{M}_{7} \mathrm{C}_{3}$ carbides decrease. TiC carbides might make a bigger contribution to the bulk hardness than $\mathrm{M}_{7} \mathrm{C}_{3}$ carbides, because the hardness of $\mathrm{TiC}$ carbides is in the range of 2000-3 $200 \mathrm{HV}^{1)}$ However, the bulk hardness of the hypereutectic HCCIs in the graphite mold shows a big scatter because the $\mathrm{TiC}$ carbides are not uniformly distributed.

The wear loss of the hypereutectic HCCIs is determined by the amount of matrix and $\mathrm{M}_{7} \mathrm{C}_{3}$ carbides, although the hardness of TiC carbides is larger than that of the $\mathrm{M}_{7} \mathrm{C}_{3}$ carbides and the matrix. However, the presence of a small amount of $\mathrm{TiC}$ carbides will not contribute to the wear loss.

It can be seen that there is a tendency of an increased wear loss with an increased Ti content in the graphite mold experiments. This is due to the decrease of the volume fraction of $\mathrm{M}_{7} \mathrm{C}_{3}$ carbides. It seems that the austenite phase ( $\gamma$ phase) which surrounds the agglomerated TiC might be easily peeled off during the wear process. This is leads to an increased Ti content. In summary, the hardness and wear loss of the hypereutectic HCCIs do not change significantly with increased Ti contents and cooling rates under as-cast conditions. 


\section{Conclusions}

The effect of cooling rate and $\mathrm{Ti}$ addition on the solidification microstructure and final properties in the hypereutectic HCCIs with the main composition of $\mathrm{Fe}-17$ mass $\% \mathrm{Cr}-$ 4 mass $\% \mathrm{C}$ was studied. Based on the examination of the size distribution, composition and morphology, the $\mathrm{M}_{7} \mathrm{C}_{3}$ carbides were roughly classified into "primary $\mathrm{M}_{7} \mathrm{C}_{3}$ carbides" and "eutectic $\mathrm{M}_{7} \mathrm{C}_{3}$ carbides" with a $11.2 \mu \mathrm{m}$ border size. The obtained results may be summarized as follows:

(1) With an increased cooling rate, the maximum size of primary $\mathrm{M}_{7} \mathrm{C}_{3}$ carbides decreased from 151.9 to $53.9 \mu \mathrm{m}$ and the number of eutectic $\mathrm{M}_{7} \mathrm{C}_{3}$ carbides increased from $0.81 \times 10^{3} \mathrm{~mm}^{-2}$ to $4.80 \times 10^{3} \mathrm{~mm}^{-2}$. Moreover, the volume fraction of $\mathrm{M}_{7} \mathrm{C}_{3}$ carbides decreased with an increased cooling rate. So, a low cooling rate is more close to the equilibrium state.

(2) With an increased Ti content, the maximum size of the primary $\mathrm{M}_{7} \mathrm{C}_{3}$ carbides decreased from151.9 to $27.0 \mu \mathrm{m}$ in the graphite mold due to the precipitation of $\mathrm{TiC}$ during cooling and solidification of the melt. However, the size and number of eutectic $\mathrm{M}_{7} \mathrm{C}_{3}$ carbides did hardly change (from $2.00 \times 10^{3} \mathrm{~mm}^{-2}$ to $2.84 \times 10^{3} \mathrm{~mm}^{-2}$ ). In addition, the total volume fraction of $\mathrm{M}_{7} \mathrm{C}_{3}$ carbides decreased with an increased $\mathrm{Ti}$ content due to a reaction between $\mathrm{C}$ and $\mathrm{Ti}$.

(3) $\mathrm{TiC}$ carbides with high formation temperatures can not only act as nuclei of $\mathrm{M}_{7} \mathrm{C}_{3}$ carbides, but they also contain a core, $\mathrm{Ti}(\mathrm{C}, \mathrm{N})$. The size and number of TiC carbides both increase with an increased $\mathrm{Ti}$ addition. It was also found that $\mathrm{TiC}$ carbides precipitation was not obviously affected by the cooling rate.

(4) The bulk hardness increased with a slight increase of a $\mathrm{Ti}$ addition, due to $\mathrm{TiC}$ carbide precipitation. However, the results were scatted. The wear loss increased as the amount of $\mathrm{Ti}$ increases in the graphite mold. This is due to that the volume fraction of $\mathrm{M}_{7} \mathrm{C}_{3}$ carbides decreased.

\section{Acknowledgements}

Qiang Liu acknowledges fruitful discussions with assistant Prof. Kai Wang in Professor Qiang Wang's group at Northeastern University. He also would like to thank the China Scholarship Council (CSC) for financial support of his research.

\section{REFFERENCES}

1) Ö. N. Dogan, J. A. Hawk and J. H. Tylczak: Wear, 250 (2001), 462.

2) H. G. Fu, X. J. Wu, X. Y. Li, J. D. Xing, Y. P. Lei and X. H. Zhi: J. Mater. Eng. Perform., 18 (2009), 1109.

3) X. J. Wu, J. D. Xing, H. G. Fu and X. H. Zhi: Mater. Sci. Eng. A, 457 (2007), 180.

4) X. H. Zhi, J. D. Xing, H. G. Fu and Y. M. Gao: Mater. Charact., 59 (2008), 1221.

5) R. J. Chung, X. Tang, D.Y. Li, B. Hinckley and K. Dolman: Wear, 267 (2009), 356.

6) M. M. Arikan, H. Çimenoglu and E. S. Kayali: Wear, 247 (2001), 231.

7) A. Bedolla-Jacuinde, R. Correa, J. G. Quezada and C. Maldonado: Mater. Sci. Eng. A, 398 (2005), 297.

8) A. Bedolla-Jacuinde, R. Correa, I. Mejia, J. G. Quezada and W. M. Rainforth: Wear, 263 (2007), 808.

9) A. Bedolla-Jacuinde, S. Aguilar and C. Maldonado: J. Mater. Eng. Perform., 14 (2005), 301.

10) Q. Chen and B. Sundman: Mater. Trans., 43 (2002), 551

11) H. W. Zhang, Ch.-A. Gandin, J. C. He and K. Nakajima: IOP Conf. Ser.: Mater. Sci. Eng., 33 (2012), 012061.

12) B. Sundman and Q. Chen: Thermodynamic Calculation Interface TQInterface, V7.0, Thermo-Calc Software AB, Stockholm, (2008).

13) P. Shi: TCS steels/Fe-alloys database, V6.0, Thermo-Calc Software AB, Stockholm, (2008).

14) X. H. Zhi, J. D. Xing, Y. M. Gao, H. G. Fu, J. Y. Peng and B. Xiao: Mater. Sci. Eng. A, 487 (2008), 171. 